\title{
Awareness and Self-Reported Health Hazards of Electromagnetic Waves from Mobile Phone Towers in Dhaka, Bangladesh: A Pilot Study
}

\author{
Sheikh Mohammed Shariful Islam ${ }^{1,2}$ \\ ${ }^{1}$ Center for Control of Chronic Disease (CCCD), International Center for Diarrhoeal Disease Research, Bangladesh (ICDDR,B), \\ 68 Shaheed Tajuddin Ahmed Sarani, Mohakhali, Dhaka 1212, Bangladesh \\ ${ }^{2}$ Center for International Health (CIH), Ludwig-Maximilians-Universität (LMU), Leopoldstraße 7, 80802 Munich, Germany
}

Correspondence should be addressed to Sheikh Mohammed Shariful Islam; shariful.islam@icddrb.org

Received 11 May 2014; Revised 9 August 2014; Accepted 11 August 2014; Published 20 August 2014

Academic Editor: Gudlavalleti Venkata Murthy

Copyright (c) 2014 Sheikh Mohammed Shariful Islam. This is an open access article distributed under the Creative Commons Attribution License, which permits unrestricted use, distribution, and reproduction in any medium, provided the original work is properly cited.

\begin{abstract}
Background. Over the last few years there have been concerns regarding the health effects of electromagnetic waves (EMW) produced by mobile phone base transmitter stations (BTS). Data on possible health effects of EMW in developing countries are rare. This study was conducted to determine the awareness and self-reported health hazards of EMW from the mobile phone BTS in Dhaka city. Methods. A cross-sectional study was conducted among 220 respondents living around BTS in Dhaka city. Data was collected on sociodemographic characteristics, mobile phone use, BTS and EMW awareness, and self-reported health problems. Results. The majority of respondents (92.7\%) reported to have seen a BTS but only $29.5 \%$ knows how it works and $74.5 \%$ had no knowledge about the EMW. 49\% respondents experienced sleeping disturbances while recent episodes of headache or dizziness were reported by $47 \%$ and mood change or anxiety or depression by $41 \%$. About $22 \%$ complained about other physical or mental symptoms. Conclusion. Awareness about the possible health hazards from EMW of BTS is low among the inhabitants of Dhaka city. A number of respondents mentioned recent health effects but the association with BTS could not be established.
\end{abstract}

\section{Introduction}

The world has witnessed rapid growth of mobile phones use over the past few decades. Worldwide in 2013, there were 6.8 billion mobile phone subscribers which are almost as many people on earth [1]. Similarly, the use of mobile phone in Bangladesh has increased over the past few years with the total number of mobile phone active subscribers reaching 114 million at the end of December 2013 from 26.66 million at the end of May 2007 [2]. With this growth in mobile phone use there has been inevitable increase in the number of mobile phone base transmitter stations (BTS), accompanied by public concern for possible health impacts associated with exposure to electromagnetic waves (EMW) emanating from BTS.

Base transmitter stations (BTS) are radio transmitters mounted on either free-standing masts or on buildings that facilitate wireless communication between user equipment and a network. The base station antennas serving macrocells are either mounted on free-standing towers, typically 10 $30 \mathrm{~m}$ high, on short towers on top of buildings, or attached to the side of buildings. In a typical arrangement, each tower supports three antennas, each transmitting into a $120^{\circ}$ sector. The main beam is tilted slightly downwards but does not reach ground level until the distance from the tower is at least $50 \mathrm{~m}$ (usually $50-200 \mathrm{~m}$ ). Radio signals are fed through cables to the antennas and then launched as radio waves into the area or cell, around the BTS [3]. At positions where people are exposed to the radio waves from BTS, the level of exposure is much more constant over whole body than when they are exposed to a mobile phone [4].

A survey by the World Health Organization showed radio frequency (RF) exposure from BTS range from $0.002 \%$ to $0.2 \%$ of the levels of international exposure guidelines 
depending on the proximity to the antenna and other surrounding environmental factors [5]. This is low or comparable to RF exposure from radio or television broadcast transmitters and the temperature increase is insignificant and results in no adverse health effect. Consequently, the strength of the RF field is greatest at the source and diminishes quickly with distance [6]. Access near base station antennas is often restricted where RF signal may exceed international exposure limits. Previous studies have reported that RF exposure might be associated with several adverse health effects and complaints such as cancers in children, headache, neurological changes, loss of memory, increased blood pressure, and damage to eye cells [7-11]. However, most of these studies did not find a direct association between $\mathrm{RF}$ exposure and health complaints in the study population, rather a concern for the RF exposure might be responsible for the reported health effects. In addition, these symptoms are often not independent of each other and demand further evaluation.

In Bangladesh, there has been a rapid penetration of mobile phone over the past few years. Dhaka, the capital of Bangladesh, is a mega city of about 16 million people, with an area of about $1353 \mathrm{sq} . \mathrm{km}$, and is the hub of the nation's industrial, commercial, cultural, educational, and political activities. The population is growing by an estimated $4.2 \%$ per annum, one of the highest rates amongst Asian cities. According to Far Eastern Economic Review, Dhaka will become a home of 25 million people by the year 2025. With the ever increasing number of mobile phone users, more and more BTS are being erected to support the network growth in different public areas in this city. In contrast to mobile handsets, radiation is emitted continuously from BTS and is more powerful at close quarters. Despite public concern about the safety of mobile phones and BTS, there is no published literature on the possible health effects of BTS in Bangladesh to the best of our knowledge. The objectives of this study were to determine the awareness regarding BTS and identify self-reported health problems of people living near a BTS in Dhaka city.

\section{Methods}

2.1. Study Population. A cross-sectional study was conducted among 220 adults from September to November 2009 in Dhaka city. The study population was approximately 3 million people mostly from upper and middle class living in Gulshan and Mohammadpur area, respectively. Participants were selected purposefully from the study sites. In both the study areas, the data collector first selected a house nearest to a BTS and approached many adults living in the house meeting the inclusion criteria. The eligibility criteria included adult people of both sexes, living near a BTS for at least one year, and able to provide written informed consent. The use of mobile phone and migration was not considered as sample criteria. A total of 232 participants were approached with 12 refusals mentioning lack of time and not interested in the study with a response rate of $95.5 \%$.
2.2. Data Collection. Data were collected from face-to-face interview using a structured questionnaire. The questionnaire was pretested in the fields and after necessary omission, addition, and language editing, used for data collection. Data were collected on demographic characteristics, duration of living in the current residence, use of mobile phone, knowledge and awareness about BTS and EMW, and self-reported health problems. Each participant was asked in local language if they noticed any recent changes of the following symptoms: sleeping pattern/habits, episodes of headaches/dizziness, changes in anxiety/depression, burning sensations, episodes of shaking/fits, and any other health changes over the past one year. Participants mentioning any other recent symptoms were collected and categorized into the following: mental health, cardiovascular diseases (CVD), gastrointestinal symptoms (GIT), and others/nonspecific symptoms. Participants were informed regarding the objective of the study and that participating in the study is voluntary and that they could stop at any time they wished. Also, confidentiality of the information provided was ensured that data collected will only be used for the study purpose and will not be shared with anyone else except the investigators. The study protocol was approved from the scientific and ethical review committee of School of Public Health and Life Sciences, University of South Asia, Dhaka, Bangladesh.

2.3. Data Analysis. The collected data were checked, edited, and verified to exclude any error or inconsistency. Data was coded and entered into an excel sheet. Data editing and analysis were done manually and using specific statistical software SPSS (Version 11, SPSS Corporation, Chicago, USA). Tables with frequency and percentage were prepared to demonstrate the findings.

\section{Results}

3.1. Sociodemographic Profile. Data was collected from adults aged 18 years and above from the households surrounding a BTS. The mean age of the respondents was 37.27 years. Out of 220 respondents, the majority 73 (33.2\%) was in the age group 35-44 years, 54 respondents (24.5\%) were in 2534 years age group, and the rest were in other age groups. Most of the respondents (112) reported to be living in the current residence for $12-36$-month duration (50.9\%). The mean duration of living in current residence is 38.95 months. Most of respondents were married (64.5\%) and had graduate or upper level of education (73.2\%) and service holders (57.8\%) (Table 1).

\subsection{Awareness Regarding BTS and Electromagnetic Waves} $(E M W)$. Almost all the respondents (98.6\%) reported using at least one mobile phone. The majority of respondents $(92.7 \%)$ reported to have seen a BTS either from far, on a television, or in a picture. Half of the respondents have never seen the parts of a BTS (53.2\%). About one-third of respondents $(29.5 \%)$ claimed to know how the BTS works. Respondents were not asked to explain what they knew about the BTS in technical terms and whether their knowledge 
TABLE 1: Sociodemographic characteristics of the respondents $(n=$ 220).

\begin{tabular}{|c|c|c|}
\hline Variables & Number & Percentage \\
\hline Male & 111 & 50.5 \\
\hline Female & 109 & 49.5 \\
\hline \multicolumn{3}{|l|}{ Age group (years) } \\
\hline $18-24$ & 36 & 16.4 \\
\hline $25-34$ & 54 & 24.5 \\
\hline $35-44$ & 73 & 33.2 \\
\hline $45-59$ & 47 & 21.4 \\
\hline 60 and above & 10 & 4.5 \\
\hline \multicolumn{3}{|c|}{$\begin{array}{l}\text { Duration of living in current residence } \\
\text { (months) }\end{array}$} \\
\hline $12-36$ & 112 & 50.9 \\
\hline $37-48$ & 36 & 16.4 \\
\hline $49-60$ & 35 & 15.9 \\
\hline$>60$ & 37 & 16.8 \\
\hline \multicolumn{3}{|l|}{ Religion } \\
\hline Muslim & 197 & 89.5 \\
\hline Hindu & 13 & 5.9 \\
\hline Christian & 8 & 3.6 \\
\hline Others & 2 & 0.9 \\
\hline \multicolumn{3}{|l|}{ Marital status } \\
\hline Married & 142 & 64.5 \\
\hline Unmarried & 60 & 27.3 \\
\hline Divorcee/separated & 18 & 8.2 \\
\hline \multicolumn{3}{|l|}{ Education } \\
\hline None & 6 & 2.7 \\
\hline Primary & 12 & 5.5 \\
\hline Secondary & 41 & 18.7 \\
\hline Graduate/masters & 161 & 73.2 \\
\hline \multicolumn{3}{|l|}{ Occupation } \\
\hline Unemployed & 9 & 4.1 \\
\hline Student & 31 & 14.1 \\
\hline Service & 127 & 57.8 \\
\hline Business & 18 & 8.2 \\
\hline House wife & 35 & 15.9 \\
\hline
\end{tabular}

was correct. The majority of the respondents $(74.5 \%)$ had no knowledge about the EMW (74.5\%). Anyone who selfreported that they knew about EMW was reported as Yes and thus this does not explain their exact knowledge about EMW (Table 2).

3.3. Self-Reported Health Problems. During the past one year almost half of the respondents experienced problems in sleeping patterns $(49.1 \%)$, recent episodes of headache or dizziness (47.3\%), and mood change, anxiety, or depression (41.4\%). Only 11 respondents experienced some generalized burning sensation and 4 reported episodes of shaking or fits. However, these effects were not ruled out by taking personal history of any existing previous medical conditions or diseases (Table 3).

Apart from the symptoms mentioned above, 48 respondents $21.8 \%$ ) mentioned one or more other health effects, such as mood changes/problem, buzzing in the head, hopelessness, palpitation, tachycardia, heaviness of chest, anorexia, diarrhoea, and skin diseases. These symptoms mentioned as other health effects were classified and are shown in Table 4.

\section{Discussion}

The results of our study show that awareness of EMW and BTS is low among most of the respondents. Almost half of the respondents complained of sleep disturbances, episodes of headache or dizziness, and changes in mood or anxiety/depression while smaller number of respondents mentioned other heath complaints. Respondents were selected purposely from Gulshan, an elite area of Dhaka city and Mohammadpur where most of the people are highly educated and thus the awareness of the possible harmful effects of EMW from BTS can be assumed to be much lower at the national level. A survey report from European Union showed that about one-fourth of Europeans (23\%) know that power lines, mobile communication masts, mobile phones, computers, radar equipment, household appliances, wireless computer networks, induction heaters, and antitheft devices are sources for EMW [12]. Two-thirds or more of those polled said that EMW is generated by mobile telephones (71\%) and mobile communication masts (66\%). In our study, lower rates of awareness of the harmful effects of BTS were reported.

The report published in May 2000 on "Mobile Phones and Health" by the "Independent Expert Group on Mobile Phones (IEGMP)" under the direction of Sir William Stewart describes under paragraph 3.5 various symptoms which were most commonly attributed to the base stations at the hearings: "headaches, sleep disturbance, depression, stress and tiredness" [4]. Paragraphs 3.22 and 3.23 of the report list the main concerns reported in the media about base stations: "The distance at which they were 'safe', and about the proximity to schools, homes, hospitals and residential accommodation for the elderly. Adverse aesthetic impacts were also noted. The health effects most often alleged were sleep disorders, fatigue, anxiety, stress, epileptic fits, burning sensations and shaking" [13]. In Austria there have also been various reports from the population attributing different disturbances of health and well-being to exposure to BTS [14]. The symptoms reported corresponded to a large extent to those listed in the IEGMP report. In addition, cardiac dysrhythmia, high blood pressure, forgetfulness, hearing difficulties, burning of the eyes, and susceptibility to infections were reported, which generally improved or disappeared when residents moved. Detailed clarification of these symptoms has not been performed [15]. Abdel-Rassoul and colleagues in 2007 concluded that inhabitants living nearby BTS are at risk for developing neuropsychiatric problems and some changes in the performance of neurobehavioral functions either by facilitation or inhibition [16]. 
TABLE 2: Awareness of BTS according to area of residence $(n=220)$.

\begin{tabular}{lcccc}
\hline & Gulshan & Mohammadpur & Total number & Percentage \\
\hline Seen BTS & 104 & 100 & 204 & 92.7 \\
Seen parts BTS & 50 & 53 & 103 & 46.8 \\
Knowledge BTS & 38 & 27 & 65 & 29.5 \\
Knowledge EMW & 32 & 24 & 56 & 25.5 \\
\hline
\end{tabular}

TABLE 3: Self-reported health problems by area of living.

\begin{tabular}{|c|c|c|c|c|}
\hline & Gulshan & Mohammadpur & Total number & Percentage \\
\hline \multicolumn{5}{|c|}{ Sleeping disturbances } \\
\hline Yes & 54 & 54 & 108 & 49.1 \\
\hline No & 40 & 46 & 86 & 39.1 \\
\hline Do not know & 16 & 10 & 26 & 11.8 \\
\hline \multicolumn{5}{|c|}{ Headache/dizziness } \\
\hline Yes & 53 & 61 & 104 & 47.3 \\
\hline No & 51 & 45 & 96 & 43.6 \\
\hline Do not know & 6 & 4 & 20 & 9.1 \\
\hline \multicolumn{5}{|c|}{ Changes in anxiety/depression } \\
\hline Yes & 41 & 50 & 91 & 41.4 \\
\hline No & 57 & 52 & 109 & 49.5 \\
\hline Do not know & 12 & 8 & 20 & 9.1 \\
\hline \multicolumn{5}{|c|}{ Generalized burning sensation } \\
\hline Yes & 7 & 4 & 11 & 5.0 \\
\hline No & 98 & 103 & 201 & 91.4 \\
\hline Do not know & 5 & 3 & 8 & 3.6 \\
\hline \multicolumn{5}{|c|}{ Episodes of shaking/fits } \\
\hline Yes & 3 & 1 & 4 & 1.8 \\
\hline No & 123 & 88 & 211 & 95.9 \\
\hline Do not know & 4 & 1 & 5 & 2.3 \\
\hline \multicolumn{5}{|l|}{ Any other effects } \\
\hline Yes & 27 & 21 & 48 & 21.8 \\
\hline No & 73 & 83 & 156 & 70.9 \\
\hline Do not know & 10 & 6 & 16 & 7.3 \\
\hline
\end{tabular}

TABLE 4: Classification of any other effects.

\begin{tabular}{lcc}
\hline Any other effects & Number & Percentage \\
\hline Mental health (mood disorders) & 15 & 25.4 \\
CVD (palpitation, tachycardia) & 9 & 15.2 \\
GIT (anorexia, diarrhoea) & 6 & 10.2 \\
Others/nonspecific (skin rash) & 29 & 49.2 \\
\hline Total & 59 & $100 \%$ \\
\hline
\end{tabular}

$\mathrm{CVD}=$ cardio vascular diseases, GIT = gastro intestinal systems.

Röösli et al. in 2004 concluded that "sleep disorders (58\%), headaches (41\%), nervousness or distress $(19 \%)$, fatigue $(18 \%)$, and concentration difficulties were most common complaints [17]. The results of the Röösli study comply with our study where sleep disorders were reported by $49 \%$ respondents and headache or dizziness by $47 \%$. However, the presence of nervousness or distress, fatigue and concentration difficulties were also mentioned by the respondents of this study as other symptoms and the proportion is in line with Röösli study. A study by Santini in France showed increasing frequency of complaints among participants in relation with [sic] distance from base station who reported that they were living within 300 meters of BTS in rural areas, or within 100 meters of BTS in urban areas [18]. The most common complaints were irritability, depression, loss of memory, dizziness, libido decrease, and so forth. Women significantly more often than men $(P<0.05)$ complained of headache, nausea, loss of appetite, sleep disturbance, depression, discomfort and visual perturbations. Other studies reported people living in the vicinity of base stations report [sic] various complaints mostly of the circulatory system, but also of sleep disturbances, irritability, depression, blurred vision, concentration difficulties, nausea, lack of appetite, headache and vertigo" [19-21].

In our study the distance from BTS was not measured. Also comparison between the differences in terms of males and females was not performed. But the complaints were 
almost similar which shows the importance of conducting further research to determine the effects of EMW from BTS on human health. Also, studies need to be conducted to measure the safety distance of BTS from human living and recommend national authority for policy implications. Navarro and colleagues in 2003 showed that people more exposed to radiation from mobile phone antennas in $\mathrm{La}$ Nora (operating at $1800 \mathrm{MHz}$ ) had more symptoms than those who were less exposed. Exposure was associated with discomfort, irritability, appetite loss, fatigue, headache, difficulties concentrating, and sleep disturbance. Previous studies have reported that the most exposed people had a higher incidence of fatigue, irritability, headaches, nausea, loss of appetite, sleeping disorders, depression, discomfort, difficulties concentrating, memory loss, visual disorders, dizziness, and cardiovascular problems that are almost similar with our findings [22-26]. However, most of these population based studies did not show statistically significant association of the physical symptoms reported with exposure to BTS and the adverse effects might be due to nocebo effect.

Researchers in Austria found that volunteers exposed to radiation typical of that experienced at 80 meters from a BTS experienced changes in the electrical activity of their brains and feelings of unwellness [27]. Subjects reported buzzing in the head, palpitations of the heart, unwellness, and light-headedness. The Hutter report showed that, in homes with highest exposures, people reported more unpleasant symptoms including three times as many headaches, 2.3 times the incidence of tremor, 2.5 times the incidence of cold hands/feet and concentration problems, 2.4 times the incidence of appetite loss, twice as much exhaustion, and twice as much fatigue [22]. We could not make such comparisons in this study as we did not have a control group.

There are concerns, nevertheless, about whether the emissions from all BTS are uniformly low, about whether the emissions could cause unknown health effects, and whether, with the increased use of mobile telecommunications, their output will have to rise [28]. The International Agency for Research on Cancer showed that extremely low-frequency magnetic fields are possibly carcinogenic to humans (Group 2 B) [29]. EMF was demonstrated as a possible cause for the following health outcomes by the California EMF-Program 2002: leukaemia in children and adults, brain tumor in adults, miscarriage among pregnant mothers, and motor neuron disease (MND) [30-34]. Although several risk factors have been investigated, most studies on exposure from BTS could not find a direct association between RF-EMF and health complaints but several studies found health complaints associated with concern about (visible) RF-BTS. In addition, standardized blinded experimental studies were not able to confirm associations between EMF exposure and the physical complaints of the respondents.

Limitations of the Study. This study had several limitations. First, the study was conducted in two selected areas of Dhaka city with limited sample size and convenient sampling. So the results cannot be generalized and chances of sampling bias might occur. Second, health effects mentioned by the participants were self-reported and association of the symptoms with other conditions was not ruled out. Third, there was no exclusion criteria based on personal and medical histories including those having a history of epilepsy, psychiatric disorders, or specific causes of headache. Fourth, other sources of other RF such as microwave use, duration of mobile use, and wireless devices use were not included in the study and exposure contribution from BTS and other sources could not be measured due to lack of technical expertise. Also we were not able to measure the frequency, distance, and duration of exposure from BTS due to lack of technical skills. This lack of validated and reliable exposure assessment methods challenges the feasibility of such studies. Finally, we did not include any control group, so comparison of the responses could not be made.

\section{Conclusions}

From the results of our study we cannot conclude that the health effects are direct results of the BTS. However, various studies showed the association of health hazards with EMW radiation from BTS which cannot be ignored and should be considered as a public health concern. Further studies with appropriate sample size involving a control group and measuring the source and power of the radiation according to distance from source will validate the results of this study. Bangladesh Telecommunications Regulatory Authority should take measures to ensure that the BTS are set up following international standards and at a distant that is within the safety range. The exposure limits of the EMW should be restrictive to a safety limit with regular monitoring. The health authority should ensure that the BTS have no effect on human health.

\section{Conflict of Interests}

The author declares that there is no conflict of interests regarding the publication of this paper.

\section{Author's Contribution}

Sheikh Mohammed Shariful Islam initiated the study design, data collection, data management, and analysis. The author contributed to data interpretation, critically revised the drafts, and approved the final version.

\section{Acknowledgments}

The author gratefully acknowledges the support from the study participants to provide data for the study. This study was carried out as the partial fulfillment of the degree of Masters in Public Health, UniSA School of Public Health and Life Sciences, University of South Asia.

\section{References}

[1] International Telecommunication Union, The World in 2013 ICT Facts and Figures, International Telecommunication Union, Geneva, Switzerland, 2013. 
[2] "Bangladesh Telecommunication Regulatory Commission," 2014, http://www.btrc.gov.bd/facts-and-stats.

[3] G. Neubauer, H. Haider, K. Lameds et al., "Measurement methods and legal requirements for exposure assessment next to GSM base stations," in Proceedings of the 15th International Zurich Symposium on Electromagnetic Compatibility, 2003.

[4] Independent Expert Group on Mobile Phones, "Mobile phones and health," in Independent Expert Group on Mobile Phones, S. W. Stewart, Ed., 2000.

[5] World Health Organization, Electromagnetic Fields and Public Health, 2014, http://www.who.int/peh-emf/publications/facts/ fs296/en/.

[6] International Commission on Non-Ionizing Radiation Protection, "Guidelines on limits of exposure to static magnetic fields," in Health Physics, pp. 504-514, 2009.

[7] M. Otto and K. E. von Mühlendahl, "Electromagnetic fields (EMF): do they play a role in children's environmental health (CEH)?" International Journal of Hygiene and Environmental Health, vol. 210, no. 5, pp. 635-644, 2007.

[8] A. W. Preece, S. Goodfellow, M. G. Wright et al., "Effect of $902 \mathrm{MHz}$ mobile phone transmission on cognitive function in children," Bioelectromagnetics, vol. 26, no. 7, pp. S138-S143, 2005.

[9] M. Blettner, B. Schlehofer, J. Breckenkamp et al., "Mobile phone base stations and adverse health effects: phase 1 of a populationbased, cross-sectional study in Germany," Occupational and Environmental Medicine, vol. 66, no. 2, pp. 118-123, 2009.

[10] A. P. M. Zwamborn, S. H. J. Vossen, B. J. A. Leersum, M. A. Ouwens, and W. N. Makel, "Effects of global communication system radio-frequency fields on well being and cognitive functions of human subjects with and without subjective complaints," TNO-Report FEL-03-C148, 2003.

[11] P. Elliott, M. B. Toledano, J. Bennett et al., "Mobile phone base stations and early childhood cancers: case-control study," British Medical Journal, vol. 340, articla c3077, 2010.

[12] R. Santini, P. Santini, P. Le Ruz, J. M. Danze, and M. Seigne, "Survey study of people living in the vicinity of cellular phone base stations," Electromagnetic Biology and Medicine, vol. 22, no. 1, pp. 41-49, 2003.

[13] A. Huss, J. Küchenhoff, A. Bircher et al., "Symptoms attributed to the environment-a systematic, interdisciplinary assessment," International Journal of Hygiene and Environmental Health, vol. 207, no. 3, pp. 245-254, 2004.

[14] G. Oberfeld, Precaution in Action-Global Public Health Advice Following BioInitative 2007, BioInitative Working Group, 2012.

[15] S. J. Regel, S. Negovetic, M. Röösli et al., "UMTS base stationlike exposure, well-being, and cognitive performance," Environmental Health Perspectives, vol. 114, no. 8, pp. 1270-1275, 2006.

[16] G. Abdel-Rassoul, S. Aalto, C. Haarala et al., Mobile Phone Affects Cerebral Blood Flow, 2012.

[17] M. Röösli, M. Moser, Y. Baldinini, M. Meier, and C. BraunFahrländer, "Symptoms of ill health ascribed to electromagnetic field exposure- a questionnaire survey," International Journal of Hygiene and Environmental Health, vol. 207, no. 2, pp. 141-150, 2004.

[18] R. Santini, P. Santini, J. M. Danze, P. Le Ruz, and M. Seigne, "Investigation on the health of people living near mobile telephone relay stations: I/Incidence according to distance and sex," Pathologie-Biologie, vol. 50, no. 6, pp. 369-373, 2002 (French).

[19] A. Bortkiewicz, M. Zmyślony, A. Szyjkowska, and E. Gadzicka, "Subjective symptoms reported by people living in the vicinity of cellular phone base stations: review," Medycyna Pracy, vol. 55, no. 4, pp. 345-351, 2003.

[20] G. Hyland, How exposure to mobile phone base-station signals can adversely affect humans, 2005.

[21] A. W. Preece, A. G. Georgiou, E. J. Dunn, and S. C. Farrow, "Health response of two communities to military antennae in Cyprus," Occupational and Environmental Medicine, vol. 64, no. 6, pp. 402-408, 2007.

[22] H. Hutter, H. Moshammer, P. Wallner, and M. Kundi, "Subjective symptoms, sleeping problems, and cognitive performance in subjects living near mobile phone base stations," Осcupational and Environmental Medicine, vol. 63, no. 5, pp. 307-313, 2006.

[23] E. Mohler, P. Frei, C. Braun-Fahrländer, J. Fröhlich, G. Neubauer, and M. Röösli, "Effects of everyday radiofrequency electromagnetic-field exposure on sleep quality: a cross-sectional study," Radiation Research, vol. 174, no. 3, pp. 347-356, 2010.

[24] G. Berg-Beckhoff, M. Blettner, B. Kowall et al., "Mobile phone base stations and adverse health effects: phase 2 of a crosssectional study with measured radio frequency electromagnetic fields," Occupational and Environmental Medicine, vol. 66, no. 2, pp. 124-130, 2009.

[25] G. Oberfeld, N. A. Enrique, P. Manuel, M. Ceferino, and C. Gomez-Perrretta, "The microwave syndromefurther aspects of a Spanish study," in Proceedings of the 3rd International Workshop on Biological Effects of Electromagnetic Fields (EMFs '04), Kos, Greece, 2004.

[26] A. Bortkiewicz, E. Gadzicka, A. Szyjkowska et al., "Subjective complaints of people living near mobile phone base stations in Poland," International Journal of Occupational Medicine and Environmental Health, vol. 25, no. 1, pp. 31-40, 2012.

[27] A. Fragopoulou, Y. Grigoriev, O. Johansson et al., "Scientific panel on electromagnetic field health risks: consensus points, recommendations, and rationales," Reviews on Environmental Health, vol. 25, no. 4, pp. 307-317, 2010.

[28] A. Ahlbom, A. Green, L. Kheifets, D. Savitz, and A. Swerdlow, "Epidemiology of health effects of radiofrequency exposure," Environmental Health Perspectives, vol. 112, no. 17, pp. 1741-1754, 2004.

[29] IARC Working Group on the Evaluation of Carcinogenic Risks to Humans, "Non-ionizing radiation, part 1: static and extremely low-frequency (ELF) electric and magnetic fields," IARC Monographs on the Evaluation of Carcinogenic Risks to Humans/World Health Organization, International Agency for Research on Cancer, vol. 80, pp. 1-395, 2002.

[30] R. Neutra, V. d. Pizzo, and G. M. Lee, "An evaluation of the possible risks from Electric and Magnetic Fields (EMF) from power lines, internal wiring, electrical occupations, and appliances," in California EMF Program-Final Report 2002, 2002.

[31] H. Mild, "Meta-analysis of long-term mobile phone use and the association with brain tumours," International Journal of Oncology, vol. 32, no. 5, pp. 1097-1103, 2008.

[32] P. D. Inskip, R. E. Tarone, E. E. Hatch et al., "Cellular-telephone use and brain tumors," New England Journal of Medicine, vol. 344 , no. 2, pp. 79-86, 2001. 
[33] I. Deltour, A. Auvinen, M. Feychting et al., "Mobile phone use and incidence of glioma in the nordic countries 1979-2008: consistency check," Epidemiology, vol. 23, no. 2, pp. 301-307, 2012.

[34] J. Schüz, E. Böhler, G. Berg et al., "Cellular phones, cordless phones, and the risks of glioma and meningioma (Interphone Study Group, Germany)," The American Journal of Epidemiology, vol. 163, no. 6, pp. 512-520, 2006. 


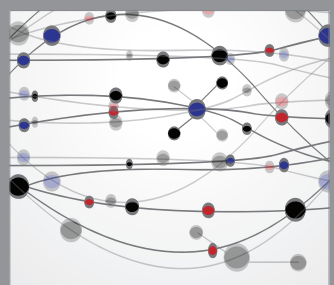

The Scientific World Journal
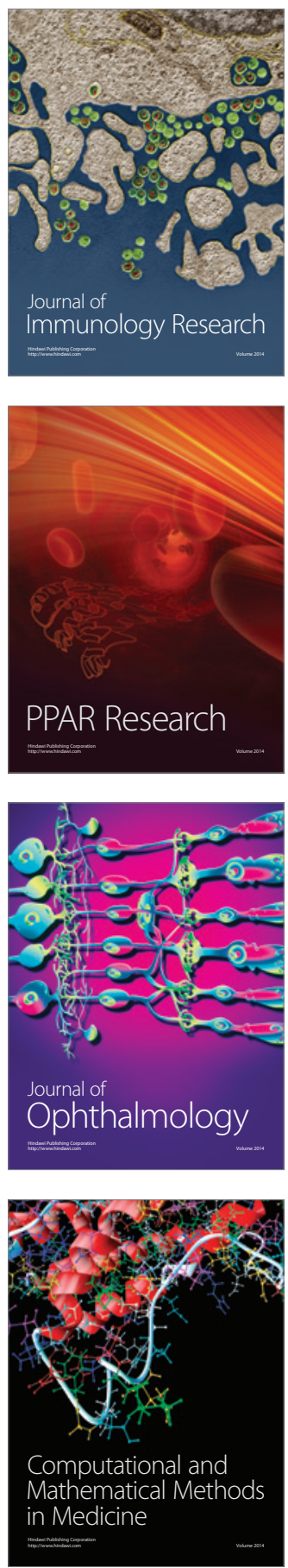

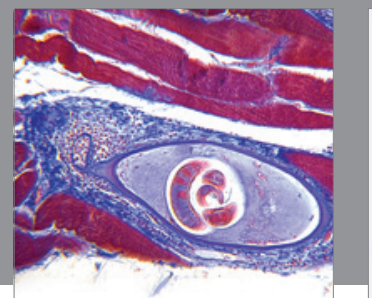

Gastroenterology

Research and Practice
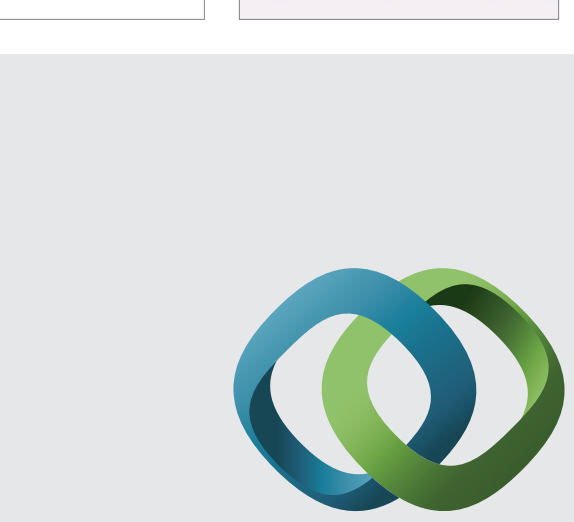

\section{Hindawi}

Submit your manuscripts at

http://www.hindawi.com
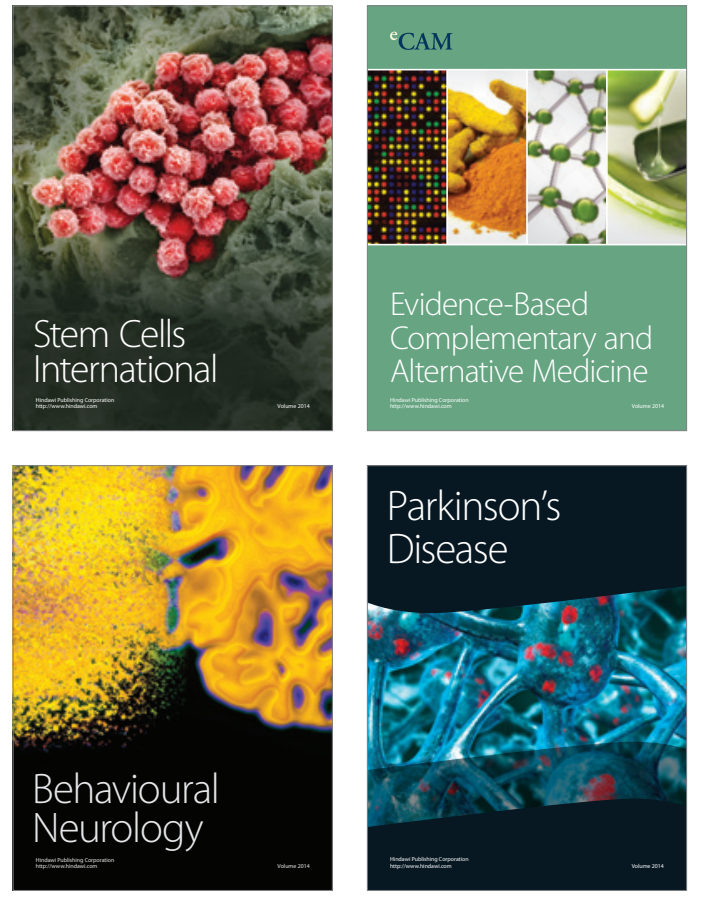
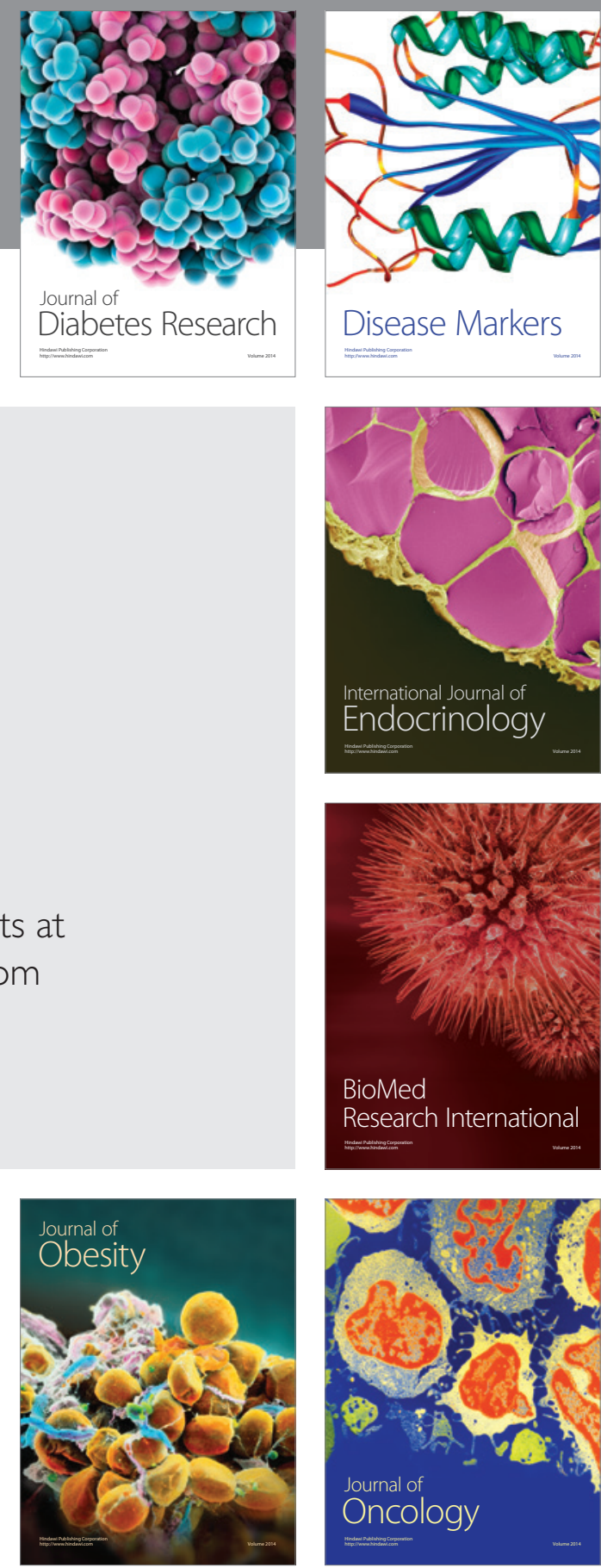

Disease Markers
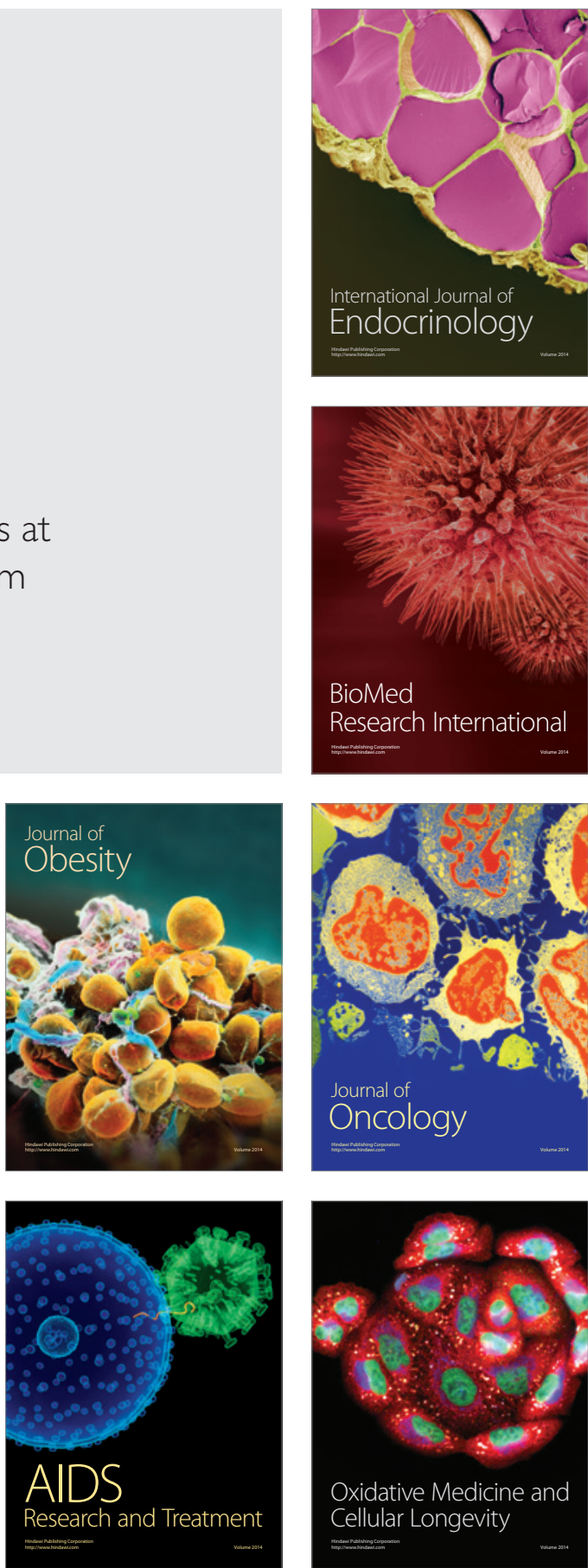